\title{
Bioactive glasses in the Management of Dentine Hypersensitivity: A Review
}

\begin{abstract}
Dentine Hypersensitivity is a common clinical condition, albeit of a low severity, and various in vitro and in vivo studies have been performed to test various approaches in managing the condition. This review investigates the use of bioactive glasses and their efficacy in treating Dentine Hypersensitivity. Significant progress was observed in the introduction of bioactive glasses in previous toothpaste formulations due to its ability to produce a Hydroxyapatite-like layer. Nevertheless, the results of the present review would suggest that a higher quality evidence was required to sufficiently support the use and effectiveness of bioactive glasses in treating Dentine Hypersensitivity. This observation is particularly pertinent in the absence of evidence relating to the effect of abrasivity of the glasses as well as the ability of strontium incorporation into the glasses. And the exact loading of the glass into dentifrice formulations. Overall, in vitro studies do appear to demonstrate that bioactive glass formulations may be an effective material to occlude dentine tubules which may in turn, reduce the fluid flow within the dentinal tubules and subsequently help manage Dentine Hypersensitivity.
\end{abstract}

Key Words: Dentine Hypersensitivity, Tubular occlusion, Bioactive Glasses, Review

\section{Introduction}

Dentine Hypersensitivity (DH) is a common clinical condition which may affect up to $74 \%$ of the population (Talioti et al., 2014). DH can be defined as a "short, sharp pain arising from exposed dentine in response to stimuli typically thermal, evaporative, tactile, osmotic or chemical and which cannot be ascribed to any other form of dental defect or pathology" (Holland et al. 1997). The condition is generally prevalent in the age 20-49 year group and may affect the facial or buccal surfaces of incisors, premolars and canines, although molars may also be affected. From a clinical perspective the loss of the overlying enamel and/or cementum may be due to a number of aetiological factors usually in combination, such as Abrasion, Attrition, Abfraction, Erosion, Gingival recession, effects of periodontal disease and/or effects of periodontal treatment (Gillam \& Orchardson 2006). According to Miglani et al., 2010 DH may also affect up to $90 \%$ of patients following non-surgical and surgical 
periodontal treatment. It is evident however that despite experiencing varying degrees of discomfort most patients did not seek treatment from their Dentist or use a desensitising toothpaste to alleviate DH (Gillam et al., 2002, Gillam 2013). Currently treatment approaches are based on the Brännström hydrodynamic theory (West et al., 2013) which required the dentine tubules to act as a capillary bore with the tubule open to the oral environment. According to this theory a stimuli (e.g..., cold air) resulted in the movement of the fluid within the dentine tubules which can be sensed by mechanical receptors near the pulp which in turn transmits the stimulus via $A \delta$ and $\mathrm{A} \beta$ fibres triggering a short, sharp pain (Brännström and Aström, 1972). A number of in vivo and in vitro studies have reported that in subjects who have either been identified as responding/not responding to a stimulus (through a clinical examination) that there was a significant difference in the appearance of the surfaces of the teeth. For example, die replicas from the clinical impressions of the teeth identified as being sensitive, when viewed under SEM indicated that there were up to 8x more patent tubules per unit area in hypersensitive dentine compared to non-sensitive dentine. These tubules also had a wider aperture (X2) compared to non- sensitive dentine (Joshi et al., 2013). According to West et al., (2013) there was no evidence of any differences between coronal and radicular dentine hypersensitivity, although it was reported that in cervical root dentine there were fewer tubules with narrower apertures compared to mid coronal dentine [6]. Joshi et al., (2013) also reported that the hydraulic conductance of coronal dentine was much higher than in radicular dentine. The evidence from conducting in vitro hydraulic conductance measurements would suggest that successfully occluding the dentinal tubules would reduce the dentinal fluid flow. Although there a number of professionally applied and At-Home products that are available for the treatment of DH, there is no current acceptance as to a gold standard product to treat DH (Gillam et al. 2013). More recently there has been renewed interest in the use of bioactive glass initially developed by Hench $(1969,1972)$ to incorporate into toothpaste formulations. The aim of this review was to evaluate the available published literature to determine whether there is sufficient evidence for the effectiveness of bioactive glass formulations in the treatment of $\mathrm{DH}$.

The discovery of bioactive glasses by Hench (1969) introduced novel synthetic materials that were capable of bonding to living tissues (Hench et al., 1972). Prior to this point, synthetic materials were designed to interact as little as possible with the human body and this often resulted in the formation of 
a non-adherent fibrous layer which encapsulated the implanted material (Hench, 2013). Hench subsequently defined bioactive materials as those materials which may instigated a biological response at the interface of the material with a subsequent bond forming between the tissue and material. The key differences between bioactive glasses (BG's) and traditionally soda-lime glasses lie in 3 main features namely 1) Less than $60 \mathrm{~mol} \%$ of Silica, 2) High levels of $\mathrm{Na}_{2} \mathrm{O}$ and $\mathrm{CaO}$, 3) High $\mathrm{CaO} / \mathrm{P}_{2} \mathrm{O}_{5}$ ratio (Shi, 2004). The original Bioglass ${ }^{\circledR}$ composition known as 45S5 was developed as a bone substitute and not as toothpaste formulation and contained $45 \% \mathrm{SiO}_{2}, 24.5 \% \mathrm{Na}_{2} \mathrm{O}, 24.5 \% \mathrm{CaO}$, and $6 \% \mathrm{P}_{2} \mathrm{O}_{5}$. According to Hench (1998) there are two main classifications of bioactive glasses (Table 1).

Table 1 Classification of BG's (Hench; 1998)

\begin{tabular}{|l|l|}
\hline Class A Bioactive glasses & $\begin{array}{l}\text { Results in osteoconduction and osteoproduction. Binds to both soft } \\
\text { and hard tissues. }\end{array}$ \\
\hline Class B Bioactive glasses & $\begin{array}{l}\text { Osteoconductive and only able to bind to hard tissues and not soft } \\
\text { tissues. }\end{array}$ \\
\hline
\end{tabular}

It was previously reported that not only does Bioglass ${ }^{\circledR}$ bind to bone but it also facilitates the regeneration of bone. Initially the bone substitute was implanted into humans as a replacement for the ossicles of the middle ear and was subsequently used as a material to repair bone defects eventually including those caused by periodontitis as well (Ali et al., 2014). There are four main methods by which genes involved with osteoblastic proliferation, differentiation, and cell to cell adhesion are upregulated namely: surface chemistry, topography, rate and type of dissolution ions and shear stress at the interface. As a result the rates of osteogenesis, angiogenesis, chondrogenesis, and differentiation of mesenchymal stem cells are increased. However, more advanced studies are required to fully appreciate the effect(s) of the bioactive glass on cell gene expression (Kaur et al., 2013). Although an increase in the transcription rates of a gene may be recorded for example of vascular endothelial growth factor, its physiological relevance is, however not fully known. Moreover, increased expression does not inherently correspond to increased protein production since post-translational mechanisms may result in a different culmination to that expected.

Further advantageous features of bioactive glasses include antimicrobial properties which may inhibit bacterial growth at the site of implantation, and further oral applications include pulp capping, 
sinus obliteration, repair of orbital floor fracture, coating for dental implants, topical endodontic disinfectants as well as being used in air-abrasion(Ali et al., 2012; Hench, 2006).

\section{Therapeutic ions, drugs and growth factors}

The original 45S5 Bioglass ${ }^{\circledR}$ contained $45 \% \mathrm{SiO} 2,24.5 \% \mathrm{Na} 2 \mathrm{O}, 24.5 \% \mathrm{CaO}$, and 6\% $\mathrm{P} 2 \mathrm{O}_{5}$, however, subsequently more research has been conducted into incorporating various therapeutic ions, drugs and growth factors into the glass structure. Table 2 outlines a variety of products that have been incorporated into the glass structure to provide a beneficial effect (Ali et al., 2012; Ali et al., 2014).

Table 2 Ion, Drug or Growth Factor and their Effects

\begin{tabular}{|c|c|}
\hline Ion, Drug or Growth Factor & Effect \\
\hline Fluoride & $\begin{array}{l}\text { Formation of Fluorapatite which is more } \\
\text { chemically stable than HCA at lower pH values } \\
\text { and so more acid resistant. Fluoride containing } \\
\text { BG result in increased alkaline phosphatase } \\
\text { activity, an indication of increased bone } \\
\text { mineralisation. Nevertheless, low fluoride } \\
\text { containing bioactive glasses demonstrated the } \\
\text { greatest cell proliferation according to } \\
\text { Gentleman et al., } 2013 \text {. } \\
\text { Inhibits bacterial enzymes. } \\
\text { Stimulates osteoblasts at a concentration of 25- } \\
500 \text { ng ml-1, whilst over } 500 \text { ng ml-1 inhibits } \\
\text { osteoblast activity. }\end{array}$ \\
\hline Strontium & $\begin{array}{l}\text { Improves demineralized dentine mineral density. } \\
\text { Increases osteoblast activity and inhibits } \\
\text { osteoclast activity. }\end{array}$ \\
\hline $\mathrm{P}_{2} \mathrm{O}_{5}$ & $\begin{array}{l}\text { Favours FAP formation instead of } \mathrm{CaF}_{2} \text {. } \\
\begin{array}{l}\text { Assists in the maintenance of network } \\
\text { connectivity. }\end{array}\end{array}$ \\
\hline Zinc & $\begin{array}{l}\text { Anti-inflammatory and anti-microbial. } \\
\text { Promotes osteoblast activity and inhibits } \\
\text { osteoclast activity }\end{array}$ \\
\hline Silver & Anti-bacterial \\
\hline Lithium & Promotes osteogenesis and cementogenesis \\
\hline Copper & $\begin{array}{l}\text { Anti-bacterial and promotes osteogenesis and } \\
\text { angiogenesis }\end{array}$ \\
\hline Iron & Promote osteogenesis \\
\hline Dexamethasone & Promote osteogenesis \\
\hline
\end{tabular}




\begin{tabular}{|l|l|}
\hline & \\
\hline Vascular Endothelial Growth Factor & Promote angiogenesis \\
\hline Ampicillin & Anti-bacterial \\
\hline Doxorubicin & $\begin{array}{l}\text { Anti-cancer drug. } \\
\text { Inhibits activity of osteosarcoma cells. }\end{array}$ \\
\hline
\end{tabular}

Additionally, the BG's are anti-bacterial in nature due to the $\mathrm{pH}$ rise associated with cation release during the surface reactions. For example, pathogens associated with both caries and periodontitis including Streptococcus mutans and Actinobacillus actinomycetemcomitas were demonstrated to be killed during in vitro studies which may demonstrate its potential anti-caries effect in a toothpaste (Jones, 2013).

Despite the degree of research, there has been limited data supporting the clinical significance of the incorporation of these products and the use of BG as a method to deliver therapeutic ions, drugs or growth factors is still in its early stage of development.

\section{Bioactive glasses and Dentine Hypersensitivity}

According to the Hydrodynamic theory the resolution of any discomfort from DH would be based on the occlusion of the open dentinal tubules which would then limit or restrict the fluid flow through dentine. Since fluid flow is directly proportional to the fourth power of the radius as indicated by Poiseuille's law, reduction of the radius of the tubule would subsequently reduce fluid flow and therefore reduce the stimulation of the mechanical receptors and nerve fibres (Lynch et al., 2012). Thus, halving the tubule radius would result in a 16 times decrease in fluid flow in the tubule.

Consequently, there are two main mechanisms through which DH may be managed. The first mechanism, has been proposed to operate via Potassium ions, e.g., Potassium Nitrate $\left(\mathrm{KNO}_{3}\right)$, Potassium Chloride or Potassium Citrate and as such does not involve tubule occlusion or affect fluid movements but rather targets the excitation of the nerve fibres. The increase in concentration of extracellular Potassium around the nerve fibres prevents their repolarization thereby blocking their excitation by inactivating their action potential (Wichgers and Emert, 1997). The second method involves occluding the exposed dentine tubules to produce a similar effect by preventing any stimuli 
initiating fluid flow to trigger the mechanoreceptors. Absi et al., (1987) and Yoshiyama et al., (1989) identified that most dentine tubules were occluded in the non-sensitive dentine in the replica dies of patients examined clinically. BG toothpaste formulation would therefore be through this method of occluding tubules to relieve $\mathrm{DH}$. The negative surface charge of the glass formed during its contact with water or saliva enables it to bind to the Type 1 collagen fibres found in dentine tubules (Greenspan, 2010). The deposition of the HCA layer that forms following the surface reactions of the glass as well as the presence of residual BG particles result in the occlusion of the tubules (Salian et al., 2010). Gillam et al., (1997) stated that to treat DH via tubule occlusion was the logical conclusion from Brännström's hydrodynamic theory.

\section{In Vitro Studies}

There is in vitro data supporting the ability of bioactive glasses, currently marketed under Sensodyne ${ }^{\circledR}$ toothpaste as Novamin ${ }^{\circledR}$, to occlude dentinal tubules. For example, Gillam et al., (2002) demonstrated via SEM micrographs that the original Bioglass ${ }^{\circledR}$ was capable of partially occluding the tubules. However, more interestingly, it showed that when bioactive glasses were used to form a new toothpaste by replacing the silica component to different degrees, it was consistently more effective in occluding tubules. Tests were conducted on dentine discs from caries-free third molars comparing new toothpaste compositions containing $0 \%, 2.5 \%$ and $7.5 \%$ bioactive glass particles. Silica is the standard filler in most toothpastes, thus the replacement of silica with BG particles ensured the validity of the study as any differences demonstrated in the SEM images of the $2.5 \%$ and $7.5 \%$ toothpastes compared to the 0\% BG control must be due to the BG particles. All compositions showed a greater tubule occlusion than the original Bioglass ${ }^{\circledR}$ formulation with increased bioactive glass levels corresponding to significantly greater tubule occlusion due to increased particle deposition on the surface and within the tubules (Gillam et al., 2002).

Particulate Bioglass ${ }^{\circledR}$ has been used for periodontal osseous repair using a size range of 70 $910 \mu \mathrm{m}$ (Zamet et al., 1997) and 300-355 $\mu \mathrm{m}$ (Schepers \& Ducheyne, 1997) and this original 45S5 Bioglass ${ }^{\circledR}$ was initially used in the Gillam et al. study to determine its ability to occlude the dentinal tubules. However it was easily displaced by rinsing and handling and subsequently the investigators 
incorporated the glass into standard toothpaste formulations to determine its effectiveness in occluding the tubules. Test dentine disc halves were treated with two Over-the-Counter toothpastes; Macleans Freshmint - a calcium carbonate-based paste (Smithkline Beecham, now GSK) and Elmex Amine Fluoride - an abrasive free paste (GABA, now Colgate), mixed in a ratio 5:1, toothpaste with the original Bioglass ${ }^{\circledR}$ material and three coded toothpaste products containing $0 \%, 2.5 \%$ and $7.5 \%$. It was concluded from this study that BG particles in a suitable toothpaste formulation may be an effective way of treating DH. A study by Burwell et al., (2010) also demonstrated the ability of BG to occlude significant numbers of tubules. Mitchell et al., (2010) however, synthesised a bioactive glass formulation via a sol-gel synthesis instead of being melt-derived and as such had an increased surface area and chemical reactivity allowing for rapid bonding to the dentine surface. Additionally, they observed that BG immediately and continuously reduced the fluid conductance across the dentine for all time periods: $0 \mathrm{hr}, 1 \mathrm{hr}, 24 \mathrm{hr}, 96 \mathrm{hr}$, and $168 \mathrm{hr}$. The occluding deposits were maintained even after brushing of the prepared teeth and their soaking in acidic solutions of different $\mathrm{pH}$ for a minimum of seven days. Burwell et al., (2010) also supported Mitchell's observations that the BG particles adhered to dentine and resisted an acid challenge. However, it should be noted that this study used bovine dentine rather than human dentine. Yassen et al., (2011) also observed that there was inconsistent data supporting the use of bovine teeth as an alternative to human teeth in erosion studies, for example, some studies suggested that there was greater wear, increased mineral loss and increased lesion depth in bovine teeth compared to human teeth whereas in other studies no differences between the two methodologies were observed. Burwell et al., (2010) also reported that Novamin ${ }^{\circledR}$ was able to provide a continuous release of Calcium which aided surface remineralization; whereas other calcium products would typically only provide an initial burst of calcium which would subsequently be diluted. Earl $e t$ al., (2011) confirmed that it was the development of a hydroxyapatite-like layer by the BG particles that occluded the tubules. Nevertheless it was apparent from the published literature that more research was required to determine the clinical effectiveness of Novamin ${ }^{\circledR}$ in the management of DH (Talioti et al., 2014).

In vitro studies have also been used to compare the effectiveness of different desensitizing agents on occluding the dentinal tubules. Using SEM imaging Joshi et al., (2013) demonstrated that 
Novamin ${ }^{\circledR}$ resulted in greater numbers of completely occluded tubules than both the Gluma desensitizer and the control. For example, the ratios of completely occluded tubules to total tubules were calculated: Novamin ${ }^{\circledR}$ scoring 0.545 ; Gluma scoring 0.402 and the control scoring 0.142 , these results were statistically significant. Moreover, the Gluma desensitizer produced a layer of $1-2 \mu \mathrm{m}$ which occluded the tubules whereas Novamin ${ }^{\circledR}$ produced a thicker layer of $2-3 \mu \mathrm{m}$. The clinical relevance of the thicker layer is important since a thicker layer would have the potential to reduce the fluid conductance in the tubules and be more resistant to acid/abrasive challenges although currently this concept has not been proven.

Further studies have demonstrated the benefits of different ionic compositions of bioactive glasses in its use as a dentifrice. Brauer et al., (2010) reported that fluoride containing glasses resulted in Fluorapatite (FAP) formation which is more acid resistant than HCA due to its lower Ka value which would suggest that incorporating bioactive glasses would provide a more effective dentifrice for treating DH. However, these investigators reported that high fluoride containing glasses mainly formed $\mathrm{CaF}_{2} \mathrm{in}$ simulated body fluid (SBF). It was hypothesised that increasing the phosphate concentration would increase the Fluorapatite formation instead of $\mathrm{CaF}_{2}$ formation. This was confirmed by Mneimne et al., (2011) who compared 6 mol\% phosphate BG to $1 \mathrm{~mol} \%$ phosphate BG and reported that an increased phosphate content did favour Fluorapatite instead of $\mathrm{CaF}_{2}$ formation in a Tris buffer solution. Furthermore, it was reported that increased phosphate levels resulted in a much more rapid apatite formation, within 6 hours for 6 mol\% phosphate compared to within 3 days for 1 mol\% phosphate concentration. A quicker rate of deposition would theoretically provide a faster relief from $\mathrm{DH}$, and a greater acid resistance would lead to reduced removal of the apatite layer. It was suggested therefore that the use of a high phosphate content and fluoride containing BG would effectively provide a Fluorapatite formation which in turn would be more acid resistant than those dentifrices forming $\mathrm{CaF}_{2}$ only. O'Donnell et al., (2009) further supported these results in a study and explained these results by suggesting that increasing the phosphate levels would in turn reduce the $\mathrm{pH}$ to a more near optimum level of $7.2 \mathrm{pH}$ which is ideal for apatite deposition. Mohammed et al., (2013) refuted the claims of previous studies that $\mathrm{CaF}_{2}$ formation was beneficial due to its ability to exhibit an anti-caries effect; form a physical barrier on enamel surface; reduce rate of demineralization and act as a fluoride reservoir. 
Instead these investigators reported that $\mathrm{CaF}_{2}$ formation reduced the $\mathrm{Ca}^{2+}$ available for remineralization which further resulted in loss of $\mathrm{PO}_{4}{ }^{3-}$ and concluded that $\mathrm{CaF}_{2}$ formation was "potentially detrimental" as it prevents apatite formation. It was further noted that Strontium as well as Fluoride, both at concentrations $45 \mathrm{ppm}$ were capable of inhibiting the $\mathrm{CaF}_{2}$ formation. However, the study only used static models not dynamic cyclic models which would have better mimicked the oral environment. Moreover, an increase in $\mathrm{Ca}^{2+}$ and $\mathrm{PO}_{4}{ }^{3-}$ deposition may also lead to an increase in calculus formation. Nonetheless, the addition of Fluoride to BG's was concluded to be beneficial to oral health (Brauer et al., 2009).

\section{Abrasivity}

Ali et al., (2012) identified that BG used in a dentifrice e.g. Novamin ${ }^{\circledR}$ based on the $45 \mathrm{~S} 5$ glass was significantly harder than enamel and dentine (Table 3). This data, together with other data would suggest that some BGs could have a Mohs hardness value of $7 \mathrm{GPa}$ or more. However, this figure should ideally be below $3.5 \mathrm{GPa}$, which is the hardness of enamel, in order to prevent any tooth wear. These investigators also noted that the Fluoride and Strontium addition would result in a reduction of both hardness and abrasivity values which would be highly beneficial to be incorporated in a BG dentifrice. There are however limited and contradictory data analysing the abrasivity of BG in the published literature which also suggests the need for further work in this area. Additionally, Ali et al., (2012) indicated that there was a lack of evidence in the literature on the effect of salivary proteins on apatite deposition and emphasized the need for further research into this area.

Table 3 Mohs harness values in selected materials and structures

\begin{tabular}{|l|l|}
\hline Material & Mohs hardness \\
\hline Bioglass ${ }^{\circledR}$ & 4.5 \\
\hline Enamel & 3.5 \\
\hline Dentine & $2.0-2.5$ \\
\hline Calcium Carbonate & 3.0 \\
\hline Alumina & 9.25 \\
\hline
\end{tabular}

There are also limited data on the particle size and shape and relative abrasivity of bioactive glass particles and it has been previously reported that particles that were more rounded and less angular could be expected to have a reduced abrasivity and a direct correlation was observed between 
both particle size and abrasivity. LaTorre et al., (2010) also demonstrated that finer particle sizes of Calcium Sodium Phosphosilicates (CSPS) resulted in a greater $\mathrm{Ca}^{2+}$ and $\mathrm{PO}_{4}{ }^{3-}$ deposition. However, these studies were conducted in vitro and ideally in vivo studies are required since these variables would be considerably different in a final formulation (Ali et al., 2012). This would be particularly relevant for research into the effect on abrasion (by tooth brushing) following an acid challenge. Furthermore, as in vitro studies generally use healthy or unerupted teeth for SEM investigation, clinically teeth exposed to the norms of daily life may exhibit tooth wear and the thickness of the enamel may be reduced. This is evident particularly in the cervical area of the tooth where the enamel is at its thinnest and the dentine may be exposed. Ideally in vitro studies need to mimic the normal oral environment but sometimes this is very difficult to achieve for a number of reasons and care should be taken not to extrapolate these results in vitro studies into the clinical environment. It was also apparent that further investigation was required to analyse both particle size and shape in order to reduce abrasivity. For example, Mahmood et al., (2014) reported that increased particle size resulted in a greater enamel loss when comparing three different particle sizes of BG dentifrices: <38, 38-63 and 63-110 microns. Particles formed from percussion milling with sharp edges were reported to be significantly more abrasive than round ball milled particles. Preferential wear was observed at the Enamel Dentine Junction; considering that this area relevant for both gingival recession and $\mathrm{DH}$, it would be worthwhile to reduce the abrasivity of the dentifrice as much as possible otherwise greater wear will occur in the cervical area of the tooth. These investigators concluded that the abrasivity of a BG dentifrice was not a major problem, nevertheless, it is still advantageous to lower the abrasivity component especially when considering that the Fluorapatite layer formed is thin and can potentially be removed via abrasion [35]. Abrasives in a dentifrice can however contribute to the removal of tooth substance and initiate DH and as such it should be recommended to have a low abrasive toothpaste which will minimise tooth surface loss while being able to remove stain and plaque from the tooth surface.

The original Novamin ${ }^{\circledR}$ dentifrice did not contain strontium, and Ali et al., (2012) suggested that it would be advantageous to include Strontium in BG dentifrice due to its anti-caries effect, ability in remineralization and apatite formation; and help to reduce the abrasivity of a dentifrice. Studies specifically comparing Strontium containing Bioactive glasses to non-strontium containing dentifrices 
should be conducted in vitro and in vivo to determine whether the incorporation of Strontium into a dentifrice is relevant and clinical relevant. Further research analysing different ionic compositions of bioactive glass dentifrices including different concentrations of Strontium, Fluoride, Zinc and other ions (Table 2) should therefore by conducted to determine the optimum concentration to be used in a bioactive glass dentifrice to treat $\mathrm{DH}$.

\section{In Vivo Studies}

Litkowski et al., (2010) conducted a proof of principle study to test the bioactive glass's safety in vivo and to assess whether the in vitro occlusion of dentinal tubules translated to a clinically significant reduction in DH. This randomized, double-blinded study compared the following interventions namely $2.5 \%$ Novamin ${ }^{\circledR}, 7.5 \%$ Novamin ${ }^{\circledR}$ and a placebo (0\% Bioglass) dentifrice formulations. Using thermal air and tactile tests on 66 subjects, the Novamin ${ }^{\circledR}$ dentifrices resulted in a statistically significant greater reduction in sensitivity scores compared to the placebo. The 7.5\% Novamin ${ }^{\circledR}$ formulation resulted in the greatest reduction with no adverse events reported which appeared to support the use of a Novamin ${ }^{\circledR}$ dentifrice to relieve DH. The clinical evidence was supported by Gillam et al., (2002) in an in vitro study where the same interventions were evaluated under SEM investigation in that the $7.5 \%$ Novamin ${ }^{\circledR}$ occluded most of the tubules compared to $2.5 \%$ and $0 \%$ Novamin ${ }^{\circledR}$ which provided evidence of the potential mechanism (tubule occlusion) of the Novamin ${ }^{\circledR}$ dentifrice formulation. Gendreau et al, (2011) also provided a comprehensive summary of previous in vivo studies. In all the studies reviewed by Gendreau et al, (2011), Novamin ${ }^{\circledR}$ consistently resulted in a significantly greater reduction in all sensitivity tests compared to either a placebo or other dentifrices. However, the Talioti et al., (2014) systematic review identified the various biases present in many of these and other studies. For example, Litkowski et al., (2010) failed to provide any information concerning their randomization process or allocation concealment nevertheless, their study was still included in the Talioti et al., review unlike the Salian et al., (2010) study which was excluded due to its negative control group containing Fluoride whereas the intervention group, Novamin ${ }^{\circledR}$, did not contain Fluoride. Du et al., (2008) study was also excluded since it only provided an abstract. Studies that were only reported as an abstract were also excluded Pradeep et al., 2012 and Pradeep and Sharma, (2010) were also considered of a high quality and fitted the inclusion criteria to be incorporated in the review. However, Pradeep et al., 
(2012) did not disclose any information concerning calibration over the measure of DH and failed to sufficiently describe the placebo group. Additionally, Pradeep and Sharma, (2010) did not provide any further details regarding their randomization method which was performed via a lottery process. Most of the studies obtained in the search strategy, however, were excluded by Talioti et al. [1]. For example, 31/34 Novamin ${ }^{\circledR}$ studies were excluded and the reasons for exclusion were extensive, the investigators also commented on the heterogeneity between the various studies which made further analysis impossible. Overall, the Talioti et al., 2014 review included only three randomized controlled trials involving CSPS. Although randomized controlled trials are a high level of evidence, the small number of included studies rendered it impossible to make any definitive conclusions on the efficacy of Novamin ${ }^{\circledR}$ for treating DH. According to these investigators there was a need for further high quality studies in order to assess the effects of Novamin ${ }^{\circledR}$ formulations. It was evident that the current Novamin ${ }^{\circledR}$ products contain 5\% CSPS although Litkowski et al., (2010) clearly showed that the 7.5\% formulation was more efficacious than the $2.5 \%$ formulation. There were, however limited data on studies comparing the various concentrations of bioactive glasses based on the Novamin ${ }^{\circledR}$ patent but one possible reason for using the lower percentage of glass in the formulation was the cost of the glass particles.

Several studies have recently compared a Novamin ${ }^{\circledR}$ formulation with Potassium Nitrate $\left(5 \% \mathrm{KNO}_{3}\right)$ dentifrice formulations, for example, Acharya et al., (2013) compared a 5\% CSPS dentifrice to a 5\% $\mathrm{KNO}_{3}$ dentifrice. It was reported that although the 5\% CSPS group did result in a lower VAS score after 2 weeks of use, there were no statistically significant differences between the two groups at 4 and 8 weeks. Satyapal et al., (2014) also compared 5\% CSPS to 5\% $\mathrm{KNO}_{3}$ and reported that the CSPS group resulted in a statistically significant lower VAS scores after 3 weeks. The 60 participants were subsequently asked to discontinue using the dentifrice and then recalled after a further 3 weeks. The VAS scores increased following this discontinuation however, the 5\% CSPS group still scored significantly less than the $5 \% \mathrm{KNO}_{3}$ group after the total of 6 weeks. One of the problems of this randomised single-blind study was the limited duration of the study involving only one time point that was measured. Ideally a longer duration study with assessments at multiple time points during use and following discontinuation would be preferred. Study design is often a problem when evaluating clinical 
studies and it is important for investigators to follow the published guidelines on conducting studies when testing desensitising dentifrice formulations (Holland et al. 1997). For example, Morris et al., (1999) highlighted the need for large sample sizes due to the immense placebo effect present in DH studies. A further problem in this field is the lack of a so-called gold standard product to compare in these types of studies (Porto et al., 2009) and although some investigators have used of $\mathrm{KNO}_{3}$ dentifrice formulations in this way there is no evidence to support the use of $\mathrm{KNO}_{3}$ dentifrices in treating $\mathrm{DH}$ (Poulson et al., 2006, Karim and Gillam 2013).

\section{Conclusions}

Although the exact number of individuals suffering DH is controversial, it is undoubtedly a significant proportion of the population that complain about the problem. Overall, there appears to be promising evidence supporting the use of bioactive glasses to treat DH. In vitro evidence supports the ability of CSPS to occlude dentinal tubules whereas currently there appears to be limited in vivo evidence to support its efficacy in alleviating DH. There are also limited data in the published literature on the exact loading of CSPS glass into dentifrice formulations, abrasivity of CSPS, particle size and shape and the incorporations of various ions such as strontium and active ingredients into the bioactive glass' network structure.

\section{References}

1. Absi, E., Addy, M. and Adams, D. (1987). Dentine hypersensitivity. A study of the patency of dentinal tubules in sensitive and non-sensitive cervical dentine. Journal of Clinical Periodontology, 14(5), pp.280-284.

2. Acharya, A., Surve, S. and Thakur, S. (2013). A clinical study of the effect of calcium sodium phosphosilicate on dentin hypersensitivity. Journal of Clinical and Experimental Dentistry, pp.e18-22.

3. Ali, S., Hill, R. and Gillam, D. (2012). Dentine Hypersensitivity and Abrasivity of Bioactive Glass Toothpaste. LAP LAMBERT Academic Publishing.

4. Ali, S., Farooq, I. and Iqbal, K. (2014). A review of the effect of various ions on the properties and the clinical applications of novel bioactive glasses in medicine and dentistry. The Saudi Dental Journal, 26(1), pp.1-5.

5. Brännström M, Aström A. (1972). The hydrodynamics of the dentine; its possible relationship to dentinal pain. Int Dent J 22(2), pp.219-27.

6. Brauer, D., Karpukhina, N., O'Donnell, M., Law, R. and Hill, R. (2010). Fluoride-containing bioactive glasses: Effect of glass design and structure on degradation, $\mathrm{pH}$ and apatite formation in simulated body fluid. Acta Biomaterialia, 6(8), pp.3275-3282.

7. Burwell, A., Jennings, D., Muscle, D. and Greenspan, D. (2010). NovaMin and dentin hypersensitivity--in vitro evidence of efficacy. J Clin Dent, 21(3), pp.66-71. 
8. Schepers and Ducheyne P. (1997) Bioactive glass particles of narrow size range for the treatment of oral bone defects: a 1-24 month experiment with several materials and particle sizes and size ranges. Journal of Oral Rehabilitation, 24, 171171.

9. Earl, J., Leary, R., Muller, K., Langford, R. and Greenspan, D. (2011). Physical and chemical characterization of dentin surface following treatment with NovaMin technology. J Clin Dent, 22(3), pp.62-67.

10. Gendreau, L., Barlow, A. and Mason, S. (2011). Overview of the clinical evidence for the use of NovaMin in providing relief from the pain of dentin hypersensitivity. J Clin Dent, 22(3), pp.90-95.

11. Gentleman, E., Stevens, M., Hill, R. and Brauer, D. (2013). Surface properties and ion release from fluoride-containing bioactive glasses promote osteoblast differentiation and mineralization in vitro. Acta Biomaterialia, 9(3), pp.5771-5779.

12. Gillam, D. (1997). Clinical trial designs for testing of products for dentine hypersensitivity-a review. J West Soc Periodontol Periodontal Abstr, 45(2), pp.37-46.

13. Gillam, D., Tang, J., Mordan, N. and Newman, H. (2002). The effects of a novel Bioglass ${ }^{\circledR}$ dentifrice on dentine sensitivity: a scanning electron microscopy investigation. J Oral Rehabil, 29(4), pp.305-313.

14. Gillam, D., Bulman, J., Eijkman, M. and Newman, H. (2002). Dentists' perceptions of dentine hypersensitivity and knowledge of its treatment. J Oral Rehabil, 29(3), pp.219-225.

15. Greenspan, D. (2010). NovaMin and tooth sensitivity--an overview. J Clin Dent, 21(3), pp.6165.

16. Hench, L., Splinter, R., Allen, W., Greenlee, T. (1972). Bonding mechanisms at the interface of ceramic prosthetic materials. J Biomed Mater Res 2:117-141.

17. Hench, L. and Wilson, J. An Introduction to Bioceramics. Singapore, World Scientific Publishing, 1993.

18. Hench, L. (1998). Bioceramics. Journal of the American Ceramic Society, 81(7), pp.17051728.

19. Hench, L. (2006). The story of Bioglass®. J Mater Sci: Mater Med, 17(11), pp.967-978.

20. Hench, L. (2013). Chronology of bioactive glass development and clinical applications. New J. Glass Ceram, 3(2), pp.67-73.

21. Holland, G., Narhi, M., Addy, M., Gangarosa, L. and Orchardson, R. (1997). Guidelines for the design and conduct of clinical trials on dentine hypersensitivity*. Journal of Clinical Periodontology, 24(11), pp.808-813.

22. Jell, G. and Stevens, M. (2006). Gene activation by bioactive glasses. J Mater Sci: Mater Med, 17(11), pp.997-1002.

23. Jones, J. (2013). Review of bioactive glass: From Hench to hybrids. Acta Biomaterialia, 9(1), pp.4457-4486.

24. Joshi, S., Shivananje Gowda, A. and Joshi, C. (2013). Comparative evaluation of NovaMin desensitizer and Gluma desensitizer on dentinal tubule occlusion: a scanning electron microscopic study. J Periodontal Implant Sci, 43(6), p.269.

25. Karim, B. and Gillam, D. (2013). The Efficacy of Strontium and Potassium Toothpastes in Treating Dentine Hypersensitivity: A Systematic Review. International Journal of Dentistry, 2013, pp.1-13.

26. Kaur, G., Pandey, O., Singh, K., Homa, D., Scott, B. and Pickrell, G. (2013). A review of bioactive glasses: Their structure, properties, fabrication and apatite formation. Journal of Biomedical Materials Research Part A, 102(1), pp.254-274.

27. LaTorre, G. and Greenspan, D. (1600). The role of ionic release from NovaMin (calcium sodium phosphosilicate) in tubule occlusion: an exploratory in vitro study using radio-labeled isotopes. J Clin Dent, 21(3), pp.72-76. 
28. Litkowski, L. and Greenspan, D. (2010). A clinical study of the effect of calcium sodium phosphosilicate on dentin hypersensitivity-proof of principle. J Clin Dent, 21(3), pp.77-81.

29. Lockyer, M., Holland, D. and Dupree, R. (1995). NMR investigation of the structure of some bioactive and related glasses. Journal of Non-Crystalline Solids, 188(3), pp.207-219.

30. Lynch, E., Brauer, D., Karpukhina, N., Gillam, D. and Hill, R. (2012). Multi-component bioactive glasses of varying fluoride content for treating dentin hypersensitivity. Dental Materials, 28(2), pp.168-178.

31. Mahmood, A., Mneimne, M., Zou, L., Hill, R. and Gillam, D. (2014). Abrasive wear of enamel by bioactive glass-based toothpastes. Am J Dent, 27(5), pp.263-267.

32. Miglani, S., Aggarwal, V. and Ahuja, B. (2010). Dentin hypersensitivity: Recent trends in management. Journal of Conservative Dentistry, 13(4), p.218.

33. Mitchell, J., Musanje, L. and Ferracane, J. (2011). Biomimetic dentin desensitizer based on nano-structured bioactive glass. Dental Materials, 27(4), pp.386-393.

34. Mneimne, M., Hill, R., Bushby, A. and Brauer, D. (2011). High phosphate content significantly increases apatite formation of fluoride-containing bioactive glasses. Acta Biomaterialia, 7(4), pp.1827-1834.

35. Mohammed, N., Kent, N., Lynch, R., Karpukhina, N., Hill, R. and Anderson, P. (2013). Effects of Fluoride on in vitro Enamel Demineralization Analyzed by 19F MAS-NMR. Caries Res, 47(5), pp.421-428.

36. Morris, M., Davis, R. and Richardson, B. (2016). Clinical efficacy of two dentin desensitizing agents. Am J Dent, 12(2), pp.72-76.

37. O'Donnell, M., Watts, S., Hill, R. and Law, R. (2009). The effect of phosphate content on the bioactivity of soda-lime-phosphosilicate glasses. J Mater Sci: Mater Med, 20(8), pp.16111618.

38. Pradeep AR, Sharma A. (2010). Comparison of clinical efficacy of a dentifrice containing calcium sodium phosphosilicate to a dentifrice containing potassium nitrate and to a placebo on dentinal hypersensitivity: a randomized clinical trial. Journal of Periodontology, 81(8):1167-1173.

39. Pradeep AR, Agarwal E, Naik SB, Bajaj P, Kalra N.(2012). Comparison of efficacy of three commercially available dentifrices on dentinal hypersensitivity: a randomized clinical trial. Australian Dental Journal, 57(4):429-434.

40. Porto, I., Andrade, A. and Montes, M. (2016). Diagnosis and treatment of dentinal hypersensitivity. Journal of Oral Science, 51(3), pp.323-332.

41. Satyapal, T., Mali, R., Mali, A. and Patil, V. (2014). Comparative evaluation of a dentifrice containing calcium sodium phosphosilicate to a dentifrice containing potassium nitrate for dentinal hypersensitivity: A clinical study. Journal of Indian Society of Periodontology, 18(5), p.581.

42. Shi, D. (2004). Biomaterials and tissue engineering. Berlin: Springer-Verlag Berlin Heidelberg.

43. Talioti, E., Hill, R. and Gillam, D. (2014). The Efficacy of Selected Desensitizing OTC Products: A Systematic Review. ISRN Dentistry, 2014, pp.1-14.

44. Walters, P. (2014). Dentinal Hypersensitivity: A Review. [Online] Available at: http://www.dentalcare.com/media/en-US/education/ce200/ce200.pdf [Accessed 30 Jan 2016]

45. Wichgers, T. and Emert, R. (1997). Dentin Hypersensitivity. Oral Health, 87(3), pp.51-56.

46. Wu, C. and Chang, J. (2014). Multifunctional mesoporous bioactive glasses for effective delivery of therapeutic ions and drug/growth factors. Journal of Controlled Release, 193, pp.282-295. 
47. West, N., Lussi, A., Seong, J. and Hellwig, E. (2012). Dentin hypersensitivity: pain mechanisms and aetiology of exposed cervical dentin. Clin Oral Invest, 17(S1), pp.9-19.

48. Yassen, G., Platt, J. and Hara, A. (2011). Bovine teeth as substitute for human teeth in dental research: a review of literature. J Oral Sci, 53(3), pp.273-282.

49. Yoshiyama, M., Masada, J., Uchida, A. and Ishida, H. (1989). Scanning Electron Microscopic Characterization of Sensitive vs. Insensitive Human Radicular Dentin. Journal of Dental Research, 68(11), pp.1498-1502.

50. Zamet J.S., Darbar, U., Griffiths, G.S., Bulman, J.S., Bragger, U., Burgin, W., and Newman, H.N. (1997) Particulate bioglass as a grafting material in the treatment of periodontal intrabony defects. Journal of Clinical Periodontology, 24, 410410. 